\title{
Regulation of Phosphatidylinositol 3-Kinase Activity in Liver and Muscle of Animal Models of Insulin-resistant and Insulin-deficient Diabetes Mellitus
}

\author{
Franco Folli, Mario J. A. Saad, Jonathan M. Backer, and C. Ronald Kahn \\ Research Division, Joslin Diabetes Center, Department of Medicine, Brigham and Women's Hospital, and Harvard Medical School, \\ Boston, Massachusetts 02215
}

\begin{abstract}
Insulin stimulates tyrosine phosphorylation of insulin receptor substrate 1 (IRS-1), which in turn binds to and activates phosphatidylinositol 3-kinase (PI 3-kinase). In the present study, we have examined these processes in animal models of insulinresistant and insulin-deficient diabetes mellitus. After in vivo insulin stimulation, there was a 60-80\% decrease in IRS-1 phosphorylation in liver and muscle of the ob/ob mouse. There was no insulin stimulation of PI 3-kinase ( 85 kD subunit) association with IRS-1, and IRS-1-associated PI 3-kinase activity was reduced $90 \%$. Insulin-stimulated total PI 3-kinase activity was also absent in both tissues of the ob/ob mouse. By contrast, in the streptozotocin diabetic rat, IRS-1 phosphorylation increased $50 \%$ in muscle, IRS-1-associated PI 3-kinase activity was increased two- to threefold in liver and muscle, and there was a 50\% increase in the p85 associated with IRS-1 after insulin stimulation in muscle.

In conclusion, (a) IRS-1-associated PI 3-kinase activity is differentially regulated in hyperinsulinemic and hypoinsulinemic diabetic states; (b) PI 3-kinase activation closely correlates with IRS-1 phosphorylation; and $(c)$ reduced PI 3-kinase activity may play a role in the pathophysiology of insulin resistant diabetic states, such as that seen in the ob/ob mouse. ( $J$. Clin. Invest. 1993. 92:1787-1794.) Key words: insulin receptor kinase • insulin resistance $\bullet$ insulin receptor substrate $\bullet$ phosphatidylinositol 3-kinase $\bullet$ diabetes
\end{abstract}

\section{Introduction}

Insulin plays a central role in the regulation of blood glucose levels and acts in a coordinated fashion to stimulate protein and lipid metabolism by modifying the activity of various enzymes and/or transport proteins. Insulin effects at the cellular level are initiated by binding to the $\alpha$-subunit of its receptor with subsequent activation of the tyrosine kinase activity present in the $\beta$-subunit $(1,2)$. Substantial evidence has accumulated that the tyrosine kinase activity is instrumental for most of the downstream biological effects of insulin (3-5). In cultured cells and in the intact animal, insulin receptor activation leads to the subsequent tyrosyl phosphorylation of a cytoplas-

Address correspondence to C. Ronald Kahn, M.D., Joslin Diabetes Center, One Joslin Place, Boston, MA 02215.

Received for publication 3 February 1993 and in revised form 28 May 1993.

J. Clin. Invest.

(c) The American Society for Clinical Investigation, Inc.

$0021-9738 / 93 / 10 / 1787 / 08 \quad \$ 2.00$

Volume 92, October 1993, 1787-1794 mic protein with an apparent molecular mass of $160-185 \mathrm{kD}$ named insulin receptor substrate-1 (IRS-1 ) ${ }^{1}(6-9)$.

The exact mechanism by which IRS-1 links insulin receptors to downstream effects is unknown, but one component of this link appears to be the enzyme phosphatidylinositol 3-kinase (PI 3-kinase). PI 3-kinase activity is stimulated by a number of growth factors, including insulin and IGF-1, PDGF, EGF, colony-stimulating factor-1, hepatocyte growth factor, interleukin-2, and nerve growth factor, as well as after cell transformation $(10,11)$. This enzyme is composed of an 85$\mathrm{kD}$ regulatory subunit that contains two $\mathrm{SH} 2$ and one $\mathrm{SH} 3$ domain (11), and $110 \mathrm{kD}$ catalytic subunit that phosphorylates phosphatidylinositol and its $4^{\prime}$ and $4^{\prime}, 5^{\prime}$ phosphorylated derivatives in the D-3 position of the inositol ring (12). After insulin stimulation of cells expressing the human insulin receptor, as well as in liver and muscle of the normal intact rat, PI 3-kinase associates with specific phosphorylation motifs in IRS- 1 and is activated by this association $(8,9,13-15)$.

Insulin resistance is defined as a subnormal biologic response to a given concentration of insulin. Virtually all patients with diabetes mellitus, whether affected by insulin-dependent diabetes mellitus (IDDM) or non-insulin-dependent diabetes mellitus (NIDDM), have some degree of insulin resistance ( 5 , $16,17)$. In NIDDM, insulin resistance is fundamental to its pathogenesis. Decreased insulin receptor kinase activity has been reported in several states of insulin resistance $(6,18,19)$. We recently showed that altered IRS- 1 phosphorylation may have an important role as well $(20,20 \mathrm{a})$. In the present study, we have examined IRS- 1 association with and activation of PI-3 kinase and the levels of expression of this enzyme in the hyperinsulinemic, insulin resistant ob/ob mouse and in the hypoinsulinemic streptozotocin diabetic rat, models of NIDDM and IDDM, respectively.

\section{Methods}

Materials. Reagents for SDS-PAGE and immunoblotting were from Bio-Rad Laboratories (Richmond, CA). NP-40 was from Calbiochem (La Jolla, CA). Phosphatidylinositol was from Avanti (Alabaster, AL), silica gel thin-layer chromatography plates from Merck (Gibbstown, $\mathrm{NJ}$ ), protein A-Sepharose 6MB from Pharmacia (Upsala, Sweden), ${ }^{125}$ I-protein A from ICN Biomedicals (Costa Mesa, CA), $\left[\gamma-{ }^{32} \mathrm{P}\right]$ ATP from NEN-Du Pont (Wilmington, DE), and nitrocellulose paper (BA $85,0.2 \mu \mathrm{m}$ ) was from Schleicher \& Schuell (Keene, NH). Sodium amobarbital (Amytal) and human recombinant insulin (Humulin R) were from Lilly Research Laboratories (Indianapolis, IN). All other reagents were from Sigma Chemical Co. (St. Louis, MO). Male Sprague-Dawley rats were from Charles River Breeding Laboratories

1. Abbreviations used in this paper: IDDM, insulin-dependent diabetes mellitus; IRS-1, insulin receptor substrate-1; NIDDM, non-insulin-dependent diabetes mellitus; PI 3-kinase, phosphatidylinositol 3-kinase; STZ, streptozotocin. 
Inc., (Wilmington, MA). Male C57B $1 / 6 \mathrm{~J}$ ob/ob and their lean (ob/ + ) controls were purchased from Jackson Laboratory (Bar Harbor, ME). Polyclonal antiphosphotyrosine antibodies were raised in rabbits and affinity purified on phosphotyramine columns (21). Anti-IRS-1 antibodies were raised in rabbits using a synthetic peptide (CT) derived from the rat carboxyterminal sequence (TYASINFQKQPEDRQ) of the rat liver IRS-1 protein (8) and IgGs were partially purified with a protein A-Sepharose column. Anti-rat-PI 3-kinase antiserum (antip85) was from UBI (Lake Placid, NY). Polyclonal antibodies to a glutathione S-transferase-p85 bacterial fusion protein containing amino acids $321-724$ of the human p85 (22) were produced by injection into New Zealand white rabbits and purified protein A-Sepharose chromatography and used in immunoprecipitation experiments.

Animal methods. Male rats (130-180 g) and mice (6-8 wk) were fed standard rodent chow and water ad libitum. Food was withdrawn 12-14 $\mathrm{h}$ before experiments. Diabetes was induced in the rats with streptozotocin in $0.01 \mathrm{M}$ citrate buffer, $\mathrm{pH} 4.5$, administered intraperitoneally in a single dose of $100 \mathrm{mg} / \mathrm{kg}$ body wt to overnight-fasted rats and rats were studied $7 \mathrm{~d}$ later. Rats and mice were anesthetized with sodium amobarbital ( 15 and $20 \mathrm{mg} / \mathrm{kg}$ of body wt intraperitoneally, respectively) and were used in experiments $10-15 \mathrm{~min}$ later. The abdominal cavity was opened, the portal was vein exposed, and $1 \mathrm{ml}$ of normal saline $(0.9 \% \mathrm{NaCl})$ with or without $200 \mu \mathrm{g}$ insulin was injected.

Immunoprecipitation with anti-IRS-1 and anti-p85 antibodies. 30 and $90 \mathrm{~s}$ after insulin injection into the portal vein, liver, and hindlimb muscle, respectively, were excised and processed for immunoprecipitation experiments as previously described $(20)$. Equal protein amounts of the supernatant were used in immunoprecipitation experiments with anti-IRS- 1 antibodies $(9 \mu \mathrm{g} / \mathrm{ml}$ anti-CT $)$ or $2 \mu \mathrm{l} / \mathrm{ml}$ anti-rat-p85 antiserum and protein A-Sepharose. The samples were processed for SDS-PAGE electrophoresis and Western blotting as described (20). The blots were incubated with antiphosphotyrosine antibodies $(0.3$ $\mu \mathrm{g} / \mathrm{ml}$ anti-pY) or anti-p85 antibodies (whole antiserum 1/200 final dilution) diluted in blocking buffer overnight at $4^{\circ} \mathrm{C}$.

Immunoblotting and activity of PI 3-kinase. A portion of the left lobe of liver and the hindlimb skeletal muscle were removed and immediately homogenized in ice-cold solubilization buffer $(1 / 10 \mathrm{wt} / \mathrm{vol})$ with a generator (Polytron PTA 20S; Brinkmann Instruments, Westbury, NY) at maximum speed for $30 \mathrm{~s}$ and left to sit on ice for $30 \mathrm{~min}$.

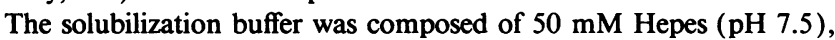
$137 \mathrm{NaCl}, 1 \mathrm{mM} \mathrm{MgCl} 2,1 \mathrm{mM} \mathrm{CaCl}, 2 \mathrm{mM} \mathrm{Na}_{3} \mathrm{VO}_{4}, 10 \mathrm{mM}$ sodium pyrophosphate, $10 \mathrm{mM} \mathrm{NaF}, 2 \mathrm{mM}$ EDTA, 1\% NP-40, 10\% glycerol, 2 $\mu \mathrm{g} / \mathrm{ml}$ aprotinin, $10 \mu \mathrm{g} / \mathrm{ml}$ antipain, $5 \mu \mathrm{g} / \mathrm{ml}$ leupeptin, $0.5 \mu \mathrm{g} / \mathrm{ml}$ pepstatin, $1.5 \mathrm{mg} / \mathrm{ml}$ benzamidine, and $34 \mu \mathrm{g} / \mathrm{ml} \mathrm{PMSF}$. Insoluble material was removed by centrifugation at $15,000 \mathrm{rpm}$ in a rotor (model 70Ti; Beckman Instruments, Palo Alto, CA) for $50 \mathrm{~min}$. The supernatant samples were then treated with Laemmli buffer (23) with $100 \mathrm{mM}$ DTT, heated in a boiling water bath for $4 \mathrm{~min}$, and aliquots ( $200 \mu \mathrm{g}$ of protein) were subjected to SDS-PAGE electrophoresis and Western blotting as described (20). The blots were incubated with antip85 antibodies (UBI) (whole antiserum $1 / 200$ final dilution) for $4 \mathrm{~h}$ at $22^{\circ} \mathrm{C}$ and washed for $60 \mathrm{~min}$. The blots were then incubated with $2 \mu \mathrm{Ci}$ of ${ }^{125} \mathrm{I}$-protein $\mathrm{A}(30 \mu \mathrm{Ci} / \mu \mathrm{g})$ in $10 \mathrm{ml}$ of blocking buffer for $1 \mathrm{~h}$ at $22^{\circ} \mathrm{C}$ and then washed again as described above for $2 \mathrm{~h} .{ }^{125} \mathrm{I}$-protein $\mathrm{A}$ bound to the anti-p85 antibodies was detected by autoradiography, and band intensities were quantitated by optical densitometry (Molecular Dynamics, Inc., Sunnyvale, CA).

After insulin injection, a portion of the liver and the hindlimb skeletal muscle were removed and processed as described above. IRS- 1 or PI 3-kinase were immunoprecipitated from aliquots of the supernatant containing $10 \mathrm{mg}$ protein with anti-IRS-1 $(9 \mu \mathrm{g} / \mathrm{ml}$ anti-CT $)$ or antihuman-p85 antibodies $(9 \mu \mathrm{g} / \mathrm{ml})$ followed by protein A-sepharose 6MB. PI 3-kinase activity in the immunoprecipitates was measured by in vitro phosphorylation of phosphatidylinositol as previously described (14).

Other analytical procedures. Plasma glucose levels were determined with a glucose analyzer (Beckman Instruments) on samples obtained when the animals were killed. Insulin was determined by a radioimmunoassay. Protein determination was performed by the Bradford dye method (Bio-Rad Laboratories) and bovine serum albumin as standard (24).

\section{Results}

Characteristics of ob/ob mice and streptozotocin diabetic animals. Table I summarizes the body weight, plasma glucose, and serum insulin levels of animals in all studies. Rats rendered diabetic by streptozotocin administration were markedly hyperglycemic and hypoinsulinemic as compared to controls. The streptozotocin diabetic rats also gained little or no weight in the $7 \mathrm{~d}$ after the induction of diabetes. By comparison, plasma glucose and serum insulin levels, as well as the body weight, were markedly increased in the ob/ob mice compared to their lean ob/+ controls.

IRS-1 phosphorylation and association with the 85-kD subunit of PI 3-kinase in muscle and liver of ob/ob mouse. We have previously shown that in liver and muscle of the ob/ob mouse, the phosphorylation of the $\beta$ subunit of the insulin receptor and IRS-1 are reduced. This is accompanied by a decrease in the insulin receptor protein level in both tissues, while IRS-1 protein levels decrease in liver and increase in muscle (20). To better define the levels of IRS-1 phosphorylation, we performed Western blot analyses of tyrosyl-phosphorylated proteins in anti-IRS-1 immunoprecipitates in the basal state and after in vivo insulin stimulation in the ob/ob and ob/+ control animals. In both liver and muscle of ob/ + mouse, a phosphotyrosine band with an apparent molecular mass of 185 $\mathrm{kD}$, consistent with IRS-1, was present in immunoprecipitates after insulin administration. By comparison, there was almost no detectable IRS-1 phosphorylation, even after insulin challenge in immunoprecipitates from liver or muscle of the ob/ob mice (Fig. 1, $A$ and $B$ ).

Insulin stimulated tyrosyl phosphorylation of IRS-1 is an essential step in the association with the $85-\mathrm{kD}$ subunit of PI 3-kinase and in the activation of its enzymatic activity $(8,9$, 13-15). To examine the association of the $85-\mathrm{kD}$ subunit of PI 3-kinase with IRS-1, the same blot was incubated with antibodies directed against the $85-\mathrm{kD}$ subunit of PI 3-kinase. A band with the expected molecular mass of the $85-\mathrm{kD}$ subunit of PI 3-kinase was present in all anti-IRS-1 immunoprecipitates (Fig. 1, $C$ and $D$ ). Furthermore, there was a clear increase in the amount of the PI 3-kinase that coprecipitated with IRS-1 in both liver and muscle after insulin administration in the ob/+ mouse, whereas no increase in p 85 could be detected in blots from the ob/ob animals after insulin stimulation.

Table I. Characteristics of ob/ob Mice and STZ Diabetic Rats

\begin{tabular}{lcclc}
\hline \multicolumn{1}{c}{ Groups } & $n$ & Body weight & Plasma glucose & Serum insulin \\
\hline & & $g$ & $m g / d l$ & $\mu U / m l$ \\
ob/+ & 12 & $17.7 \pm 0.3$ & $141 \pm 5(6)$ & $62.5 \pm 11.5(6)$ \\
ob/ob & 12 & $38 \pm 0.6$ & $386 \pm 57(6)$ & $282 \pm 59(5)$ \\
Control & 17 & $202 \pm 4$ & $111 \pm 14(10)$ & $18 \pm 3.5(7)$ \\
STZ diabetic & 17 & $169 \pm 5$ & $359 \pm 18(14)$ & $4.6 \pm 0.5(6)$ \\
& & & & \\
\hline
\end{tabular}

The data are represented as the mean \pm SEM. 

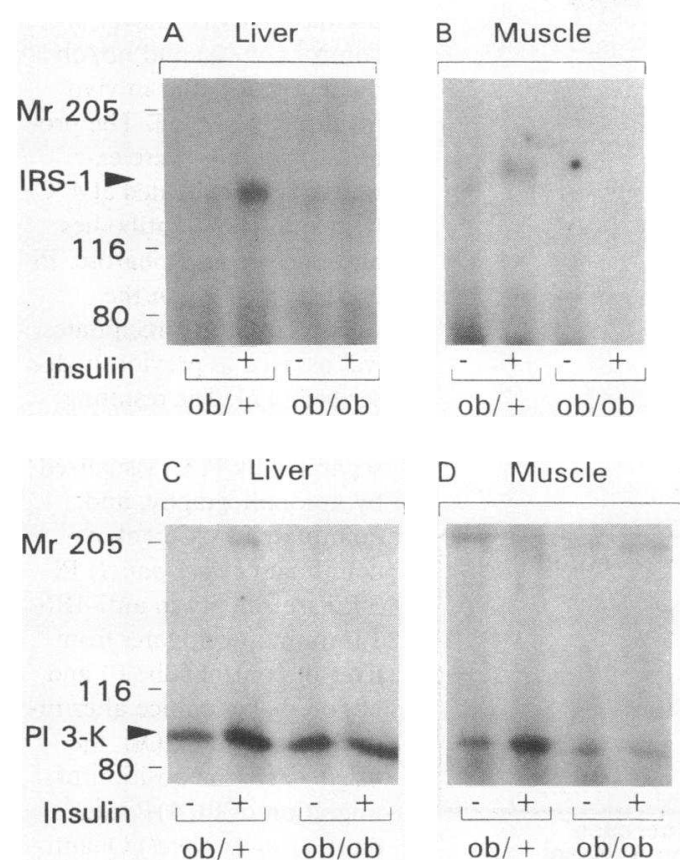

Figure 1. Western blot analysis of tyrosyl phosphorylated proteins and of PI 3-kinase ( $85 \mathrm{kD}$ subunit) in anti-IRS-1 immunoprecipitates from liver and muscle of control $(o b /+)$ and $(o b / o b)$ diabetic mice after in vivo insulin stimulation. The proteins from liver and muscle were isolated as described in Methods. Mice were anesthetized, and the abdominal wall was incised to expose the viscera. Normal saline or $200 \mu \mathrm{g}$ insulin was infused into portal vein as a bolus injection, and 30 and $90 \mathrm{~s}$ later, liver and hindlimb skeletal muscle were excised and homogenized in extraction buffer $\mathrm{A}$ at $4^{\circ} \mathrm{C}$. After centrifugation, aliquots with same amount of protein were incubated at $4^{\circ} \mathrm{C}$ with anti-IRS-1 antibodies and protein A-Sepharose. Immunoprecipitated proteins were analyzed by Western blotting with either antiphosphotyrosine antibodies ( $A$ and $B$ ) or anti-PI 3-kinase ( $85 \mathrm{kD}$ subunit) antibodies and ${ }^{125} \mathrm{I}$-protein $\mathrm{A}$, and subjected to autoradiography.

Characteristics of insulin-stimulated IRS-1-associated PI 3-kinase activity of liver and muscle in the ob/ob diabetic mouse. To determine the impact of changes in IRS-1 phosphorylation and its association with PI 3-kinase, mice were injected intraportally with insulin and PI 3-kinase activity was assayed in anti-IRS-1 immunoprecipitates from liver and muscle. A low level of basal PI 3-kinase activity was present in anti-IRS-1 immunoprecipitates from liver of ob/+ mice corresponding to a relative specific activity of $3.8 \pm 0.6 \mathrm{pmol}$ phosphate incorporated $/ \mathrm{mg}$ protein $/ \mathrm{min}$. After insulin stimulation there was a rapid five- to sixfold increase in IRS-1-associated PI 3-kinase activity $(P<0.004)$ (Fig. 2$)$. In liver of $\mathrm{ob} / \mathrm{ob}$ mice, the basal level of PI 3-kinase activity associated with IRS-1 was somewhat increased compared to controls (specific activity $=7.1 \pm 1.2 \mathrm{pmol} / \mathrm{mg}$ protein per $\mathrm{min}$ ), probably reflecting the markedly increased levels of insulin in the portal circulation of these mice. However, after insulin stimulation, IRS-1-associated PI 3-kinase activity in liver of the ob/ob mice increased only $32 \%$ above basal levels $(P=N S)$. Overall, there was a $90 \%$ reduction in insulin stimulated PI 3-kinase activity in the ob/ob mouse as compared to the ob/ + control $(P$ $<0.001$ ) (Fig. 2).

In muscle the basal level of IRS-1-associated PI 3-kinase activity was similar in ob/ + and ob/ob mice. Insulin stimu- lated IRS-1-associated PI 3-kinase activity $>30$-fold in the lean control animals, whereas in muscle of the ob/ob mice, insulin stimulated IRS-1-associated PI 3-kinase activity only $\sim$ fourfold above basal levels (Fig. 3). Thus, as in liver, muscle of ob/ob mice exhibited a $90 \%$ reduction in insulin-stimulated IRS-1-associated PI 3-kinase activity as compared to the ob/+ control $(P<0.0001)$.

Total PI 3-activity in the ob/ob mouse. To determine the extent of insulin stimulation of the total PI 3-kinase activity, a PI 3-kinase assay was performed on anti-p85 immunoprecipitates from liver and muscle of ob/ob and ob/ + mice before and after injection of $200 \mu \mathrm{g}$ insulin. Total PI 3-kinase activity in the basal state was higher in liver of ob/ob mice compared to ob/+ control animals (S.A. $7.7 \pm 1$ vs $5.6 \pm 0.5 \mathrm{pmol} / \mathrm{mg}$ protein per min), although this difference was not statistically significant. Insulin caused a 65 and $80 \%$ increase in the PI 3-kinase activity immunoprecipitable with anti-p85 antibodies in liver and muscle of the ob/+ control animals, respectively. By contrast, there was no evidence of insulin stimulation in the total PI 3-kinase activity, as detected by immunoprecipitation with antibodies directed against the 85-kD subunit of PI 3-kinase, in liver and muscle of ob/ob mice (Table II). Immunoblotting experiments on liver and muscle extracts with an antibody to the 85-kD subunit of PI 3-kinase revealed a decrease in the levels of enzyme protein in ob/ob mice to $66 \pm 8 \%$ ( $P$ $<0.02)$ and to $75 \pm 3 \%(P<0.001)$ of control levels in liver and muscle, respectively (data not shown). Although these changes are highly statistically significant, they are not sufficient to account for the decrease in IRS-1-associated or total PI 3-kinase activity. The inability of insulin to stimulate the total pool of PI 3-kinase activity, as well as the IRS-1-associated pool of PI 3-kinase activity, in both liver and muscle of ob/ob mice further emphasizes the importance of IRS-1 phosphorylation in the association/activation of PI 3-kinase.

We have previously shown that after insulin stimulation in the normal intact rat, phosphorylated IRS- 1 can also be detected is present in anti-p85 immunoprecipitates. To examine the molecular mechanisms underlying the lack of stimulation of total PI 3-kinase activity, we performed Western blot analyses on anti-p85 immunoprecipitates from both liver and muscle of ob/ob mice using antiphosphotyrosyl antibodies. In both muscle and liver, a tyrosyl phosphorylated protein with the expected molecular weight of IRS-1 was present after insulin stimulation in ob/ + control animals; this is not observed in the tissues of the obese ob/ob mice (Fig. 4).

IRS-1 phosphorylation and association with the 85-kD subunit of PI 3-kinase in muscle of streptozotocin (STZ) diabetic rats. As a comparison to the hyperinsulinemic ob/ob mouse, we performed similar studies in hypoinsulinemic STZ diabetic rats. Western blot analysis of tyrosyl phosphorylated proteins in anti-IRS-1 immunoprecipitates in muscle of STZ diabetic and control rats revealed a phosphotyrosine band with the expected molecular weight of IRS-1 after intraportal insulin administration. As previously noted (20), insulin stimulated IRS-1 phosphorylation was increased in muscle of STZ diabetic rats (Fig. $5 \mathrm{~A}$ ). When the same blot was subsequently incubated with antibodies directed against the $85-\mathrm{kD}$ subunit of PI 3-kinase, a band with the expected molecular mass of the 85-kD subunit of PI 3-kinase was present in all anti-IRS-1 immunoprecipitates. There was a twofold increase in the amount of the $85-\mathrm{kD}$ subunit of PI 3-kinase that coprecipitated 


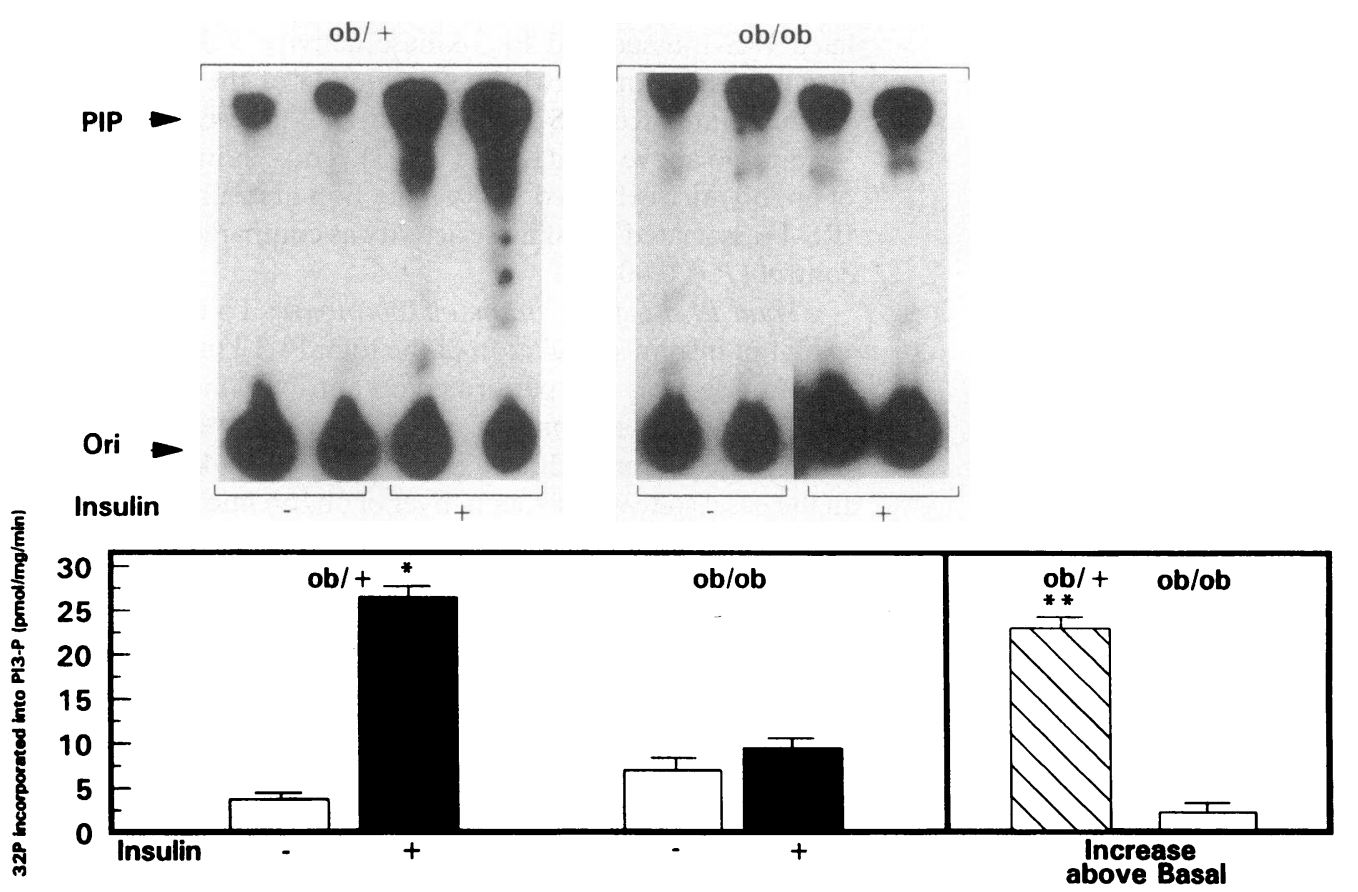

Figure 2. IRS-1-associated PI 3-kinase activity in liver of control $(o b /+)$ and ob/ob diabetic mice after in vivo insulin stimulation. The proteins from liver were extracted and incubated at $4^{\circ} \mathrm{C}$ with anti-IRS-1 antibodies and protein A-Sepharose. PI 3-kinase activity in the washed immunoprecipitates was assayed as previously described (17). The resulting labeled lipids were extracted, separated by TLC, visualized by autoradiography, and quantitated by Cerenkov counting. (Upper panel) PI 3-kinase activity in anti-IRS1 immunoprecipitates from liver of control $(o b /+)$ and ob/ob diabetic mice after insulin stimulation. Ori, the origin; PIP, the position of migration of PI(4)P standard. (Lower panel) Quantitation by Cerenkov counting of the $\left[{ }^{32} \mathrm{P}\right]$ phosphate incorporated into PI(3)P in immunoprecipitates from liver of control $(o b /+)$ and ob/ob diabetic mice after insulin stimulation. The calculated activity of PI 3-kinase (expressed as picomoles of phosphate per milligram per minute incorporated into phosphatidylinositol $)$ are as follows $(\mathrm{ob} /+)$ : basal $=3.8 \pm 0.6$, insulin stimulated $=26.6 \pm 1.2 ;(\mathrm{ob} / \mathrm{ob})$ : basal $=7.1 \pm 1.2$, insulin stimulated $=9.5 \pm 1.0$; increase above basal $(\mathrm{ob} /+)=22.9 \pm 1.5$; increase above basal $(\mathrm{ob} / \mathrm{ob})=2.4 \pm 1.8$. The values are expressed as mean $\pm \mathrm{SEM}$ of three separate experiments, each performed in duplicate. ${ }^{*}$ Differences from basal level in control (ob/+) mice at $P<0.004 ;{ }^{* *}$ Differences from increase above basal activity after insulin stimulation in ob/ob mice at $P<0.001$.

$\mathbf{o b} /+$

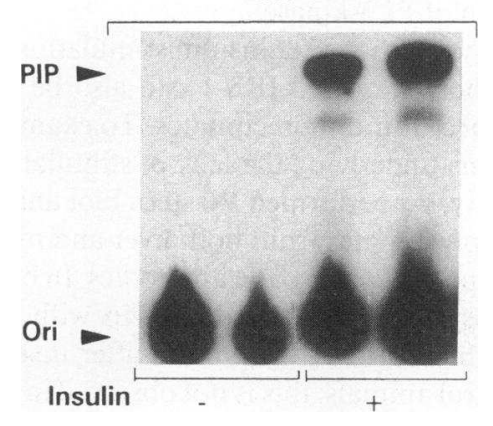

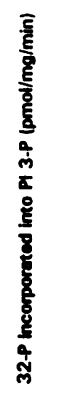

$$
\text { Insulin }
$$$$
+
$$

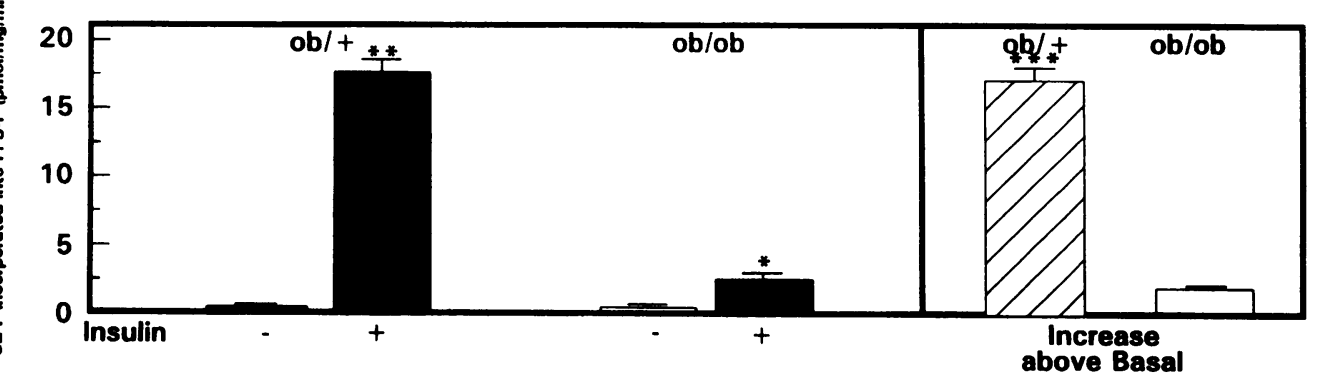

ob/ob

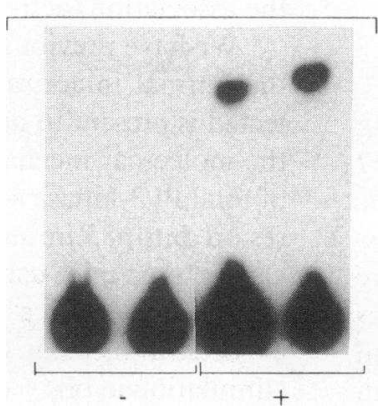

above Basal
Figure 3. IRS-1-associated PI 3-kinase activity in muscle of control $(o b /+)$ and ob/ob diabetic mice after in vivo insulin stimulation. The proteins from muscle were extracted and incubated at $4^{\circ} \mathrm{C}$ with anti-IRS-1 antibodies and Protein A-sepharose, and the PI 3-kinase activity in the washed immunoprecipitates was assayed as previously described (17). (Upper panel) PI 3-kinase activity in anti-IRS-1 immunoprecipitates from muscle of control $(o b /+)$ and ob/ob dia-

betic mice after insulin stimulation. (Lower panel) Quantitation by Cerenkov counting of the $\left[{ }^{32} \mathrm{P}\right]$ phosphate incorporated into PI( 3$) \mathrm{P}$ in immunoprecipitates from muscle of control $(o b /+)$ and ob/ob diabetic mice after insulin stimulation. The calculated activity of PI 3-kinase (expressed as picomoles of phosphate $/ \mathrm{mg} / \mathrm{min}$ incorporated into phosphatidylinositol) are as follows: $(\mathrm{ob} /+)$ : basal $=0.5 \pm 0.1$, insulin stimulated $=17.6 \pm 1.0 ;(\mathrm{ob} / \mathrm{ob})$ : basal $=0.5 \pm 0.06$, insulin stimulated $=2.6 \pm 0.3 ;$ increase above basal $(\mathrm{ob} /+)=17.1 \pm 1.0$; increase above basal $(\mathrm{ob} /$ $o b)=2.0 \pm 0.4$. The results are expressed as mean $\pm S E M$ of three separate experiments, each performed in duplicate. ${ }^{*}$ Differences from basal level in ob/ob mice at $P<0.04 ;{ }^{* *}$ Differences from basal level in control $(\mathrm{ob} /+)$ mice at $P<0.004 ;{ }^{* * *}$ Differences from increase above basal level after insulin stimulation in ob $/ \mathrm{ob}$ mice at $P<0.0001$. 
Table II. PI 3-kinase Activity in Liver and Muscle of Control $(o b /+)$ and ob/ob Diabetic Mice and Liver of Control and $S T Z$ Diabetic rats

\begin{tabular}{|c|c|c|c|}
\hline & Basal & $\begin{array}{c}\text { PI 3-kinase activity } \\
\text { +Insulin }\end{array}$ & Increase above basal \\
\hline & \multicolumn{3}{|c|}{$\mathrm{pmol} / \mathrm{mg} / \mathrm{min}$} \\
\hline \multicolumn{4}{|l|}{ Liver } \\
\hline $\begin{array}{l}\text { ob/t } \\
\text { ob/ob }\end{array}$ & $\left.\begin{array}{r}5.6 \pm 0.54 \\
7.72 \pm 1.04\end{array}\right\} \mathrm{NS}$ & $\left.\begin{array}{l}9.18 \pm 0.9 \\
7.77 \pm 0.69\end{array}\right\} \mathrm{NS}$ & $\left.\begin{array}{l}3.54 \pm 0.48 \\
0.05 \pm 0.45\end{array}\right\} P<0.01$ \\
\hline \multicolumn{4}{|l|}{ Muscle } \\
\hline $\begin{array}{l}\text { ob/+ } \\
\text { ob/ob }\end{array}$ & $\left.\begin{array}{l}6.00 \pm 0.58 \\
6.38 \pm 0.34\end{array}\right\} \mathrm{NS}$ & $\left.\begin{array}{l}10.8 \pm 1.9 \\
7.41 \pm 0.77\end{array}\right\} \mathrm{NS}$ & $\left.\begin{array}{c}4.8 \pm 1.32 \\
1.03 \pm 0.4\end{array}\right\} P<0.04$ \\
\hline \multicolumn{4}{|l|}{ Liver } \\
\hline Control rats & $1.59 \pm 0.07\} \mathrm{NS}$ & $4.87 \pm 0.28\} \mathrm{NS}$ & $3.26 \pm 0.21\} \mathrm{NS}$ \\
\hline STZ diabetic & $1.83 \pm 0.15 \mathrm{~J}$ & $4.85 \pm 0.17\}$ & $3.02 \pm 0.02\}$ \\
\hline
\end{tabular}

The proteins from liver and muscle were extracted and incubated at $4^{\circ} \mathrm{C}$ with anti-PI 3-kinase antibodies and Protein A-sepharose. PI 3-kinase activity in the immunoprecipitates was assayed as previously described (14). The results are expressed as mean \pm SEM of six separate experiments $(\mathrm{ob} /+$ and $\mathrm{ob} / \mathrm{ob}$ mice) and of three separate experiments (control and STZ diabetic rats) each performed in duplicate.

with IRS-1 in muscle after insulin administration in control rats (Fig. $5 \mathrm{~B}$ ). The amount of p85 present in anti-IRS-1 immunoprecipitates both in the basal state and after insulin stimulation was further increased in STZ diabetic rats compared to control (Fig. 5 B).

Characteristics of insulin-stimulated IRS-1-associated PI 3-kinase activity of liver and muscle in STZ diabetic and control rats. In the extracts of liver from both STZ diabetic and control rats there was a low level of basal PI 3-kinase activity in anti-IRS-1 immunoprecipitates of corresponding to a S.A. of $\cong 0.2 \mathrm{pmol} / \mathrm{mg}$ protein $/ \mathrm{min}$. After insulin stimulation, there was a fivefold increase in control rats $(P<0.01)$ and a 14-fold increase $(P<0.05)$ in STZ diabetic rats in IRS-1-associated PI 3-kinase activity (Fig. $6 \mathrm{~A}$ ). Substracting basal activity, there

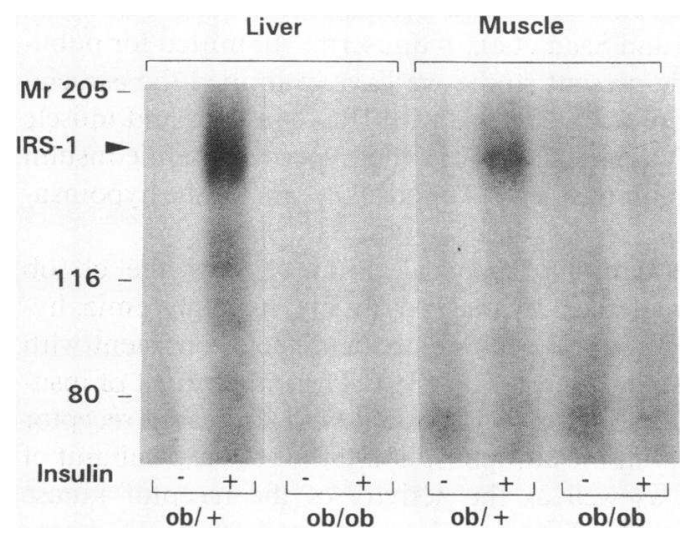

Figure 4. Western blot analysis of tyrosyl phosphorylated proteins in anti-PI 3-kinase ( $85 \mathrm{kD}$ subunit) from liver and muscle of control $(\mathrm{ob} /+)$ and ob/ob diabetic mice after in vivo insulin stimulation. The proteins from liver and muscle of $\mathrm{ob} /+$ and $\mathrm{ob} / \mathrm{ob}$ mice were extracted, processed, and incubated at $4^{\circ} \mathrm{C}$ with anti-PI 3-kinase antibody (p85) antibodies and Protein A-Sepharose. Immunoprecipitated proteins were analyzed by immunoblotting with antiphosphotyrosine antibodies and ${ }^{125} \mathrm{I}$-protein $\mathrm{A}$ and subjected to autoradiography.
A Anti-Phosphotyrosine Antibody

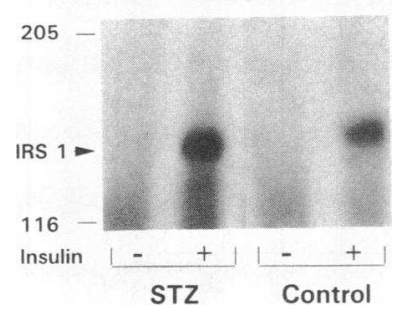

B Anti-PI 3-Kinase Antibody (85 kD Subunit)

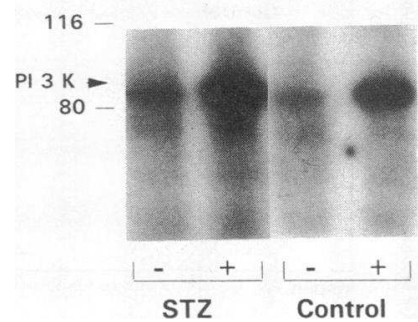

Figure 5. Western blot analysis of tyrosyl phosphorylated proteins and PI 3-kinase ( $85 \mathrm{kD}$ subunit) in anti-IRS-1 immunoprecipitates from muscle of control and STZ diabetic rats after in vivo insulin stimulation. The proteins from muscle of control and STZ diabetic rat were extracted, processed, and incubated at $4^{\circ} \mathrm{C}$ with anti-IRS-1 antibody and Protein A Sepharose. Immunoprecipitated proteins were analyzed by immunoblotting with antiphosphotyrosine antibodies $(A)$ and anti-PI 3-kinase antibody (p85) antibodies $(B)$ and ${ }^{125}$ I-protein $A$ and subjected to autoradiography.

was a threefold increase in insulin stimulated, IRS-1-associated PI 3-kinase activity in the STZ diabetic rats as compared to the controls $(P<0.03)$. In muscle, IRS-1-associated PI 3-kinase activity showed a similar pattern (Fig. $6 \mathrm{~B}$ ). After insulin stimulation there was a 10-fold increase in IRS-1-associated PI 3-kinase activity in control rats, whereas in the STZ diabetic rats there was almost 20 -fold stimulation. This corresponds to a twofold increase in insulin stimulated PI 3-kinase activity in the STZ diabetic rat compared to control ( $P$ $<0.02)$. Thus, after insulin stimulation, STZ diabetic rats showed a significantly higher stimulation of IRS-1-associated activity in both liver and muscle when compared to control rats.

Total PI 3-kinase in the STZ diabetic rat. To determine the extent of insulin stimulation of the total PI 3-kinase activity, a PI 3-kinase assay was performed on anti-p85 immunoprecipitates from liver of STZ diabetic and control rats before and after injection of insulin. In the basal state, PI 3-kinase activity in liver of STZ diabetic and control animals corresponded to relative specific activities of $1.8 \pm 0.15$ and $1.6 \pm 0.07 \mathrm{pmol} / \mathrm{mg}$ protein per min, respectively. Insulin caused a threefold stimulation of the total PI 3-kinase activity in both STZ diabetic and control animals to a maximal level of $\sim 4.9 \mathrm{pmol} / \mathrm{mg}$ protein per min (Table II). Thus, although IRS-1-associated PI 3-kinase activity was increased after insulin stimulation in STZ diabetic rats, insulin stimulated total PI 3-kinase activity was similar in the two experimental groups. Furthermore, no significant changes in the levels of the $85-\mathrm{kD}$ subunit of PI 3-kinase could be detected by immunoblotting in liver and muscle extracts of the STZ diabetic rats compared to control rats (data not shown ) and Western blot analysis using antiphosphotyrosyl antibodies on anti-p85 immunoprecipitates from liver extracts revealed a band with the expected molecular weight of IRS-1 after insulin stimulation in both STZ diabetic and control animals of similar intensity (Fig. 7).

\section{Discussion}

The molecular events linking the insulin receptor tyrosine kinase to its final cellular actions is a matter of continuing inves- 
A Liver

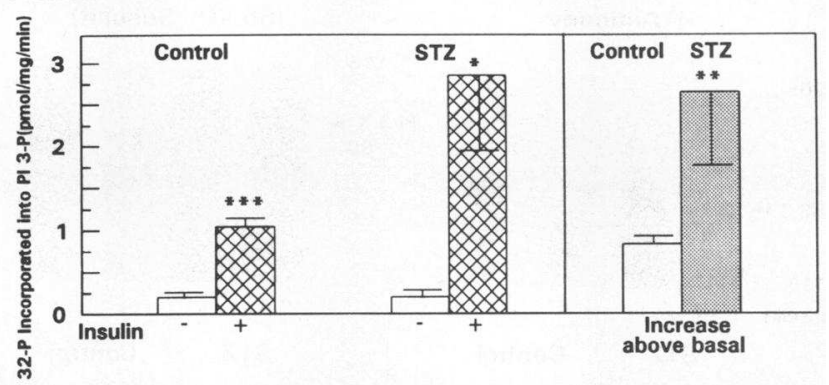

B Muscle

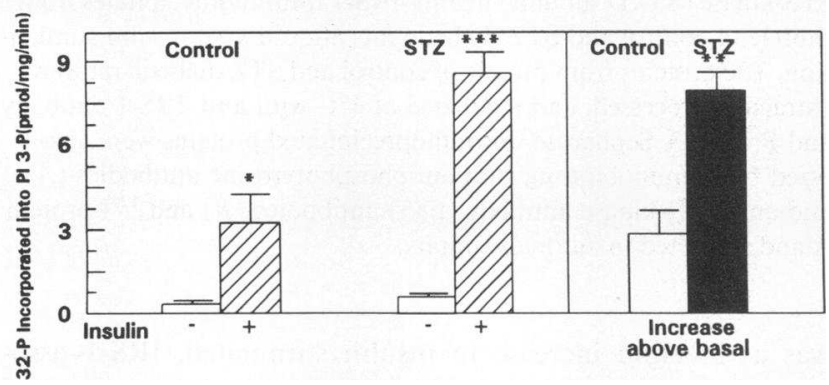

Figure 6. IRS-1-associated PI 3-kinase activity in liver and muscle of control and STZ diabetic rats after in vivo insulin stimulation. The proteins from both tissues were extracted, processed, and incubated at $4^{\circ} \mathrm{C}$ with anti-IRS-1 antibodies and protein A-Sepharose. PI 3-kinase in the washed immunoprecipitates was assayed as previously described (17). ( $A$ ) Liver. The calculated activity of PI 3-kinase (expressed as pmol phosphate/mg per min incorporated into phosphatidylinositol) are as follows: (control): basal $=0.2 \pm 0.04$, insulin stimulated $=1.0 \pm 0.1 ;(\mathrm{STZ})$ : basal $=0.2 \pm 0.1$, insulin stimulated $=2.8 \pm 0.72$; increase above basal (control) $=0.8 \pm 0.1$; increase above basal $(\mathrm{STZ})=2.65 \pm 0.72$. $(B)$ Muscle. The calculated activity of PI 3-kinase (expressed as picomoles of phosphate per milligram per minute incorporated into phosphatidylinositol) are as follows: (control $)$ : basal $=0.3 \pm 0.1$, insulin stimulated $=3.3 \pm 1.2 ;(\mathrm{STZ})$ : basal $=0.46 \pm 0.05$, insulin stimulated $=8.4 \pm 0.8$; increase above basal $($ control $)=3.0 \pm 1.0$; increase above basal $(\mathrm{STZ})=7.9 \pm 0.8$. The results are expressed as mean \pm SEM of four separate experiments, each performed in duplicate. *Differences from basal level in control rats at $P<0.05$; * Differences from increase above basal level after insulin stimulation in control rats at $P<0.03$; ${ }^{* * *}$ Differences from basal level in STZ diabetic rats at $P<0.01$.

tigation. Recently, two early steps in the insulin action cascade have been characterized at a molecular level. First, insulin stimulates tyrosine phosphorylation of a cytosolic protein of apparent molecular mass of $165-185 \mathrm{kD}$ termed IRS-1 in most (if not all) insulin responsive cells (6-9). IRS-1 fulfills the criteria of a direct substrate of the insulin receptor in vivo and in vitro $(6-9,13,14)$, and consistent with this hypothesis, IRS-1 phosphorylation is decreased in intact cells expressing kinase-deficient insulin receptor mutants $(25,26)$. From a biochemical point of view IRS- 1 is characterized by the presence of multiple potential serine, threonine and tyrosine phosphorylation sites (8). Nine of the tyrosine sites are in the motifs $Y(M / X) X M$, which are known to be phosphorylated by the purified insulin receptor kinase with high affinity (27). Similar $Y(M / X) X M$ motifs have been identified in a number of receptors for growth factors and several oncoproteins and, when phosphorylated, have been suggested to serve as intracellular binding sites for

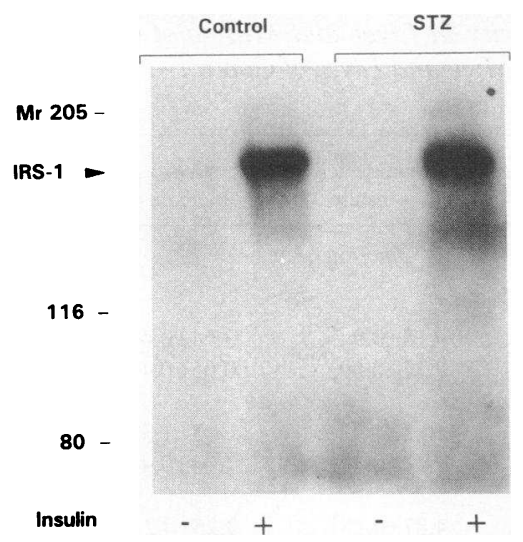

Figure 7. Western blot analysis of tyrosyl-phosphorylated proteins in anti-PI 3-kinase ( $85 \mathrm{kD}$ subunit) from liver of control and STZ diabetic rats after in vivo insulin stimulation. The proteins from liver of control and STZ diabetic rat were extracted and processed as described in legend of Fig. 1 , and incubated at $4^{\circ} \mathrm{C}$ with anti-PI 3-kinase antibody (p85) antibodies and Protein A-Sepharose. Immunoprecipitated proteins were analyzed by immunoblotting with antiphosphotyrosine antibodies and ${ }^{125} \mathrm{I}$-protein $\mathrm{A}$, and subjected to autoradiography.

proteins containing SH2 domains (11). Thus, tyrosine phosphorylation of IRS-1 leads to a second intracellular step in insulin action, an association of phosphorylated IRS- 1 with the enzyme PI 3-kinase $(8,9,13-15)$. The association occurs through phosphorylated YMXM or YXXM motifs on IRS-1 and the $\mathrm{SH} 2$ domains on the 85-kD subunit of the PI 3-kinase and results in activation of the catalytic activity of the PI 3-kinase $(15,28,29)$. Other SH2 containing proteins, such as phospholipase-C- $\gamma$ and ras-GTPase-activating protein, which efficiently bind and activated by the PDGF receptor (30), fail to interact with IRS-1 (13), further emphasizing the specificity of the IRS-1/PI 3-kinase interaction. These data, along with the time course and the dose response of production of PI 3-P and the related metabolites PI $3,4-P_{2}$ and PI 3,4,5- $P_{3}$, are consistent with the hypothesis that the PI 3-kinase products may act as messengers in growth factor action, although their physiologic role remains uncertain (11). We have previously shown a major impairment in IRS-1 phosphorylation in liver and muscle in two animal models of insulin resistance, i.e. the ob/ob mouse model of NIDDM and the dexamethasone-treated rat (reference 20 and Saad et al., manuscript submitted for publication). In the present study, we have examined the association/activation of PI 3-kinase with IRS-1 in liver and muscle and total PI 3-kinase activity, in the hyperinsulinemic insulin resistant ob/ob mouse model of NIDDM and in the hypoinsulinemic streptozotocin diabetic rat.

From the pathophysiological point of view the ob/ob mouse is characterized by marked obesity, hyperglycemia, hyperinsulinemia, and several metabolic defects consistent with peripheral insulin insensitivity (31). The impairment of insulin action in this model is associated with decreased receptor number (32), but the autophosphorylation of the $\beta$ subunit of the receptor, as well as the activity of the receptor kinase against exogenous substrates, when corrected per insulin receptor, appear to be normal $(20,33)$. In the current study, we find that both the levels of phosphorylated IRS-1 and of the $85-\mathrm{kD}$ subunit of the PI 3-kinase associated with IRS-1 are also markedly reduced, and this leads to a marked impairment in the association/activation of IRS-1 with PI 3-kinase after in vivo insulin stimulation in both liver and muscle of the ob/ob mouse. Furthermore, while insulin is capable of stimulating a $60-80 \%$ increase in the total pool of PI 3-kinase activity in the 
$\mathrm{ob} /+$ control mouse, there is no detectable stimulation of PI 3-kinase in either liver or muscle of the ob/ob mouse. Accordingly, tyrosyl-phosphorylated IRS-1 is present in anti-p85 immunoprecipitates after insulin stimulation in the ob/ + control mouse, but not detectable in anti-p85 immunoprecipitates of the ob/ob mouse. The level of the $85-\mathrm{kD}$ subunit of the PI 3-kinase as detected by immunoblotting were reduced to 66 and $75 \%$ of control levels in liver and muscle of the ob/ob mouse. The levels of this protein appear to be inversely related to circulating insulin levels, suggesting that insulin may play a role in the regulation of PI 3-kinase expression. Consistent with our previous findings (14), the 85-kD subunit of the PI 3-kinase is not tyrosine phosphorylated after insulin stimulation in either the ob/+ and the ob/ob mouse.

Kelly et al. have recently shown that in rat adipocytes the majority of insulin stimulated, antiphosphotyrosine immunoprecitable PI 3-kinase activity is concentrated in the low density microsomes fraction (34). The low density microsomes are a heterogeneous membrane fraction enriched also in GLUT4 glucose transporters $(35,36)$. These investigators have hypothesized that PI 3-kinase in the low density microsomes is associated with a vescicle that cycles between the plasma membrane and the intracellular membranes. Interestingly, the 110-kD subunit of PI 3-kinase share a significant degree of homology with VPS34, a yeast protein involved in vacuolar protein sorting $(12,37)$. A defect in the skeletal muscle glucose transporter translocation in the obese Zucker rat has been recently described (38). Since the level of phosphorylation of pp 185 (IRS-1) in response to insulin is lower in adipocytes from humans with NIDDM (6), it is tempting to hypothesize that defective IRS-1 phosphorylation and PI 3-kinase activation in the muscle of the ob/ob mouse may be involved in the defective glucose transport that is observed in both animal models (39) and in human NIDDM (40). Thus, the reduced level of phosphorylation of IRS-1 and the marked impairment of the activation of PI 3-kinase activation after insulin stimulation may play a major role in the insulin resistance observed in the ob/ob mouse.

Insulin resistance is also observed in humans with IDDM (16) and in animal models of insulinopenic diabetes despite increased insulin binding (20). Glucose clamp studies have mapped the defects in glucose metabolism to both the hepatic (increased glucose production) and muscular level (decreased glucose disposal $(41,42)$. Insulin-stimulated glucose uptake is reduced when measured in vitro in either isolated or perfused skeletal muscles from STZ diabetic rats $(43,44)$. Tissue or circulating factors such as fatty acids, counterregulatory hormones, and acidosis may antagonize the stimulatory action of insulin on glucose transport in muscle (45). In vitro studies have provided conflicting results as to the role of the insulin receptor kinase in this insulin resistance (46-49). We and others have recently shown that after acute insulin stimulation in vivo insulin receptor autophosphorylation per receptor in liver and muscle of STZ diabetic animals is decreased $(20,50)$. However IRS-1 phosphorylation is increased in muscle and in liver of STZ rats after acute insulin stimulation $(20,50)$. Consistent with these findings, we now find that after acute insulin stimulation IRS-1 phosphorylation is increased in muscle of STZ diabetic rats as compared to controls, and the amount of PI 3-kinase associated with phosphorylated IRS-1 is increased in anti-IRS-1 immunoprecipitates. Furthermore, insulin-stim- ulated IRS-1-associated PI 3-kinase activity is increased twoto threefold in both liver and muscle of STZ diabetic rats as compared to controls. Thus increased IRS-1 phosphorylation is accompanied by a significant increase in IRS-1-associated PI 3-kinase activity, consistent with an amplification of the signal in the insulin signaling pathway involving $\beta$ subunit autophosphorylation, IRS-1 phosphorylation and PI 3-kinase activity. However, the levels of the 85-kD subunit of PI 3-kinase and insulin-stimulated total PI 3-kinase activity were similar in STZ and control rats. These phenomena could be interpreted as an attempt of target tissues to compensate for the insulin deficiency and suggest that in the STZ rat, insulin resistance is neither at the level of IRS-1 phosphorylation nor at the level of PI 3-kinase activation (references 20,50 , and present study). Recent studies in Chinese hamster ovary cells overexpressing both IRS-1 and insulin receptors have shown there may be a delicate balance between the levels of IRS- 1 and insulin receptor in terms of signaling the insulin action cascade (9). Thus, there is an increase in insulin response when IRS-1 alone is overexpressed, but a decrease in insulin response when both IRS-1 and insulin receptors are overexpressed simultaneously. Since IRS-1 contains multiple YMXM/YXXM motifs, it is possible that hyperphosphorylation of IRS-1 could be detrimental, as the density of molecules associated with a single molecule of IRS- 1 may be reduced if the concentration of phosphorylated IRS-1 is too high to the point where cross-talk no longer occurs (9).

In conclusion, the insulin resistance observed in vivo in the hypoinsulinemic STZ diabetes is associated with increased IRS-1 phosphorylation and PI 3-activation in liver and muscle. By contrast, there is a striking reduction of IRS- 1 phosphorylation and PI 3-activation in liver and muscle of the ob/ob mice, and this may play an important role in this insulin resistant state. Further studies on the coupling between PI 3-kinase activation and the metabolic downstream effects of insulin may shed light to the pathogenesis of insulin resistance in different disease states.

\section{Acknowledgments}

The authors wish to thank Drs. Morris F. White and Robert J. Smith for kindly providing antiphosphotyrosine antibodies and Ms. TerriLyn Bellman for secretarial assistance.

This work was supported in part by National Institutes of Health grants DK 33201 (C. R. Kahn), DK 36836 (Joslin's Diabetes and Endocrinology Research Center grant), an American Diabetes Association Career Development Award (J. M. Backer), and the Marilyn Simpson Family Trust. Dr. Franco Folli is a recipient of Dottorato di Ricerca, University of Milano School of Medicine, Milan, Italy.

\section{References}

1. Massague, J., P. F. Pilch, and M. P. Czech. 1981. Electrophoretic resolution of three major insulin receptor structures with unique subunit stoichiometries. Proc. Natl. Acad. Sci. USA. 77:7137-7141.

2. Kasuga, M., F. A. Karlsson, and C. R. Kahn. 1982. Insulin stimulates the phosphorylation of the 95,000-dalton subunit of its own receptor. Science (Wash. DC). 215:185-187.

3. Rosen, O. M. 1987. After insulin binds. Science (Wash. DC). 237:14521458.

4. Taylor, S. I., T. Kadowaki, H. Kadowaki, D. Accili, A. Cama, C. McKeon. 1990. Mutations in insulin-receptor gene in insulin-resistant patients. Diabetes Care. 13:257-279. 
5. Moller, D. E., and J. S. Flier. 1991. Insulin resistance. Mechanisms, syndromes, and implications. N. Engl. J. Med. 325:938-948.

6. Thies, R. S., J. M. Molina, T. P. Ciaraldi, G. R. Freidenberg, and J. M. Olefsky. 1990. Insulin receptor autophosphorylation and endogenous substrate phosphorylation in human adipocytes from control, obese and NIDDM subjects. Diabetes. 39:250-258.

7. Rothenberg, P. L., W. S. Lane, A. Karasik, J. M. Backer, M. F. White, and C. R. Kahn. 1991. Purification and partial sequence analysis of pp185, the major cellular substrate of the insulin receptor tyrosine kinase. J. Biol. Chem. 266:8302-8311.

8. Sun, X.-J., P. Rothenberg, C. R. Kahn, J. M. Backer, E. Araki, P. Wilden, D. A. Cahill, B. J. Goldstein, and M. F. White. 1991. Structure of the insulin receptor substrate IRS-1 defines a unique signal transduction protein. Nature (Lond.). 352:73-77.

9. Sun, X-J., M. Miralpeix, M. G. Myers, Jr., E. M. Glasheen, J. M. Backer, C. R. Kahn, and M. F. White. 1992. Expression and function of IRS-1 in insulin signal transmission. J. Biol. Chem. 267:22662-22672.

10. Endemann, G., K. K. Yonezawa, and R. Roth. 1990. Phosphatidylinositol kinase or an associated protein is a substrate for the insulin receptor tyrosine kinase. J. Biol. Chem. 265:396-400.

11. Cantley, L. C., K. R. Auger, C. L. Carpenter, B. Duckworth, A. Graziani, R. Kapeller, and S. Soltoff. 1991. Oncogenes and signal transduction. Cell. 64:281-302.

12. Hiles, I. D., M. Otsu, S. Volinia, M. J. Fry, I. Gout, R. Dhand, G. Panayotou, F. Ruiz-Larrea, A. Thompson, N. F. Totty, et al. 1992. Phosphatidylinositol 3-kinase: structure and expression of the $110 \mathrm{kd}$ catalytic subunit. Cell. 70:419429.

13. Hadari, Y. R., E. Tzahar, O. Nadiv, P. Rothenberg, C. T. Roberts, Jr., D. LeRoith, Y. Yarden, and Y. Zick. 1992. Insulin and insulinomimetic agents induce activation of phosphatidylinositol 3'-kinase upon its association with pp185 (IRS-1) in intact rat livers. J. Biol. Chem. 267:17483-17486.

14. Folli, F., M. J. A. Saad, J. M. Backer, and C. R. Kahn. 1992. Insulin stimulation of phosphatidylinositol 3-kinase and association with insulin receptor receptor substrate 1 in liver and muscle of the intact rat. J. Biol. Chem. 267:22171-22177.

15. Backer, J. M., M. G. Myers, Jr., S. E. Shoelson, D. J. Chin, X.-J. Sun, M. Miralpeix, P. Hu, B. Margolis, E. Y. Skolnik, J. Schlessinger, and M. F. White. 1992. Phosphatidylinositol 3 '-kinase is activated by association with IRS-1 during insulin stimulation. EMBO (Eur. Mol. Biol. Organ.) J. 9:3469-3479.

16. DeFronzo, R., R. Hendler, and D. Simonson. 1982. Insulin resistance is a prominent feature of insulin-dependent diabetes mellitus. Diabetes. 31:795-801.

17. DeFronzo, R., R. C. Bonadonna, and E. Ferranini. 1992. Pathogenesis of NIDDM: a balanced overview. Diabetes Care. 15:318-368.

18. Caro, J. F., O. Ittopp, W. J. Pories, D. Meelheim, E. G. Flickinger, F. Thomas, M. Jenquin, J. F. Silverman, P. G. Khazanie, and M. K. Sinha. 1986. Studies on the mechanism of insulin resistance in the liver from humans with non-insulin-dependent diabetes. J. Clin. Invest. 78:249-258.

19. Obermaier-Kusser, B., M. F. White, D. E. Pongratz, Z. Su, B. Ermel, C. Muhlbacher, and H. U. Haring. 1989. A defective intramolecular autoactivation cascade may cause the reduced kinase activity of the skeletal muscle insulin receptor from patients with non-insulin-dependent diabetes mellitus. J. Biol. Chem. 264:9497-9504.

20. Saad, M. J. A., E. Araki, M. Miralpeix, P. L. Rothenberg, M. F. White, and C. R. Kahn. 1992. Regulation of insulin receptor substrate-1 in liver and muscle of animal models of insulin resistance. J. Clin. Invest. 90:1839-1849.

20a. Saad, M. J. A., F. Folli, J. A. Kahn, and C. R. Kahn. 1993. Modulation of insulin receptor insulin receptor substrate-1 in phosphatidylinositol 3-kinase in liver and muscle of dexamethanose-treated rats. J. Clin. Invest. 1993. 92:20652072.

21. Pang, D. T., B. R. Sharma, and J. A. Shafer. 1985. Purification of the catalitically active phosphorylated form of insulin receptor kinase by affinity chromatography with O-phosphotyrosil-binding antibodies. Arch. Biochem. Biophys. 242:176-186.

22. Hu, P., B. Margolis, E. Y. Skolnik, R. Lammers, A. Ulrich, and J. Schlessinger. 1992. Interactions of PI 3-kinase-associated p85 with EGF and PDGF receptors. Mol. Cell. Biol. 12:981-990.

23. Laemmli, U. K. 1970. Cleavage of structural proteins during the assembly of the head of bacteriophage T4. Nature (Lond.). 227:680-685.

24. Bradford, M. M. 1976. A rapid and sensitive method for the quantitation of microgram quantities of protein utilizing the principle of protein dye binding. Anal. Biochem. 72:248-254.

25. White, M. F., J. N. Livingston, J. M. Backer, V. Lauris, T. J. Dull, A. Ulrich, and C. R. Kahn. 1988. Mutation of the insulin receptor at tyrosine 960 inhibits signal transmission but does not affect its tyrosine kinase activity. Cell. 54:641-649.

26. Wilden, P. A., K. Siddle, E. Haring, J. M. Backer, M. F. White, and C. R. Kahn. 1992. The role of insulin receptor kinase domain autophosphorylation in receptor-mediated activities. J. Biol. Chem. 267:13719-13727.
27. Shoelson, S. E., S. Chatterjee, M. Chaudhuri, and M. F. White. 1992. Proc. Natl. Acad. Sci. USA. 89:2027-2031.

28. Lavan, B. E., M. R. Kuhne', C. W. Garner, D. Anderson, M. Anderson, M. Reedjik, T. Pawson, and G. E. Lienhard. 1992. The association of insulin-elicited phosphotyrosine proteins with src homology 2 domains. J. Biol. Chem. 267:11631-11636.

29. Yonezawa, K., H. Ueda, K. Hara, K. Nishida, A. Ando, A. Chavanieu, H. Matsuba, K. Shii, K. Yokono, Y. Fukui, et al. 1992. Insulin-dependent formation of a complex containing an 85-kDa subunit of phosphatidylinositol 3-kinase and tyrosine phosphorylated insulin receptor substrate 1. J. Biol. Chem. 267:2595825966.

30. Fantl, W. J., J. A. Escobedo, G. A. Martin, C. W. Turck, M. del Rosario, F. McCormick, and L. T. Williams. 1992. Distinct phosphotyrosine on a growth factor receptor bind to specific molecules that mediate different signaling pathways. Cell. 69:413-423.

31. Mordes, J. P., and A. A. Rossini. 1985. Animal models of diabetes mellitus. In Joslin's Diabetes Mellitus. A. Marble, L. P. Krall, R. F. Bradley, H. R. Christlieb, and J. S. Soeldner, editors. Lea and Febiger, Malvern, PA. 110-137.

32. Soll, A. H., C. R. Kahn, and D. M. Neville, Jr. 1975. Insulin binding to liver plasma membranes in the obese hyperglycemic (ob/ob) mouse. J. Biol. Chem. 250:4702-4707.

33. Vicario, P., E. J. Brady, E. E. Slater, and R. Superstein. 1987. Insulin receptor tyrosine kinase activity in unaltered in ob/ob and $\mathrm{db} / \mathrm{db}$ mouse skeletal muscle membranes. Life Sci. 41:1233-1241.

34. Kelly, K. L., N. B. Ruderman, and K. S. Chen. 1992. Phosphatidylinositol-3-kinase in isolated rat adipocytes. J. Biol. Chem. 267:3423-3428.

35. Simpson, I. A., D. R. Yver, P. J. Hissin, L. J. Wardzala, E. Karnieli, L. B. Salans, and S. W. Cushman. 1983. Insulin-stimulated translocation of glucose transporters in the isolated rat adipose cells: characterization of subcellular fractions. Biochim. Biophys. Acta. 763:363-407.

36. Blok, J., E. M. Gibbs, G. E. Lienhard, J. W. Slot, and H. J. Geuze. 1988. Insulin-induced translocation of glucose transporters from post-Golgi compartments to the plasma membrane of 3T3-L1 adipocytes. J. Cell Biol. 106:69-76.

37. Herman, P. K., and S. D. Emr. 1990. Characterization of VPS34, a gene required for vacuolar protein sorting and vacuole segregation in Saccharamyces cerevisiae. Mol. Cell. Biol. 12:981-990.

38. King, P. A., E. D. Horton, M. F. Hirshman, and E. S. Horton. 1992. Insulin resistance in obese Zucker rat ( $\mathrm{fa} / \mathrm{fa}$ ) skeletal muscle is associated with a failure of glucose transporter translocation. J. Clin. Invest. 90:1568-1575.

39. Le Marchand-Brustel, Y., B. Jeanrenaud, and P. Freychet. 1978. Insulin binding and effects in isolated soleus muscle of lean and obese mice. Am. J. Physiol. 234:E348-E358.

40. Dohm, G. L., E. B. Tapscott, W. J. Pories, D. J. Dabbs, E. G. Flickinger, D. Meelheim, T. Fushiki, S. M. Atkinson, C. W. Elton, and J. F. Caro. 1988. An in vitro human muscle preparation suitable for metabolic studies. Decreased insulin stimulation of glucose transport in muscle from morbidly obese and diabetic subjects. J. Clin. Invest. 82:486-494.

41. Nishimura, H., H. Kuzuya, M. Okamoto, K. Yamada, A. Kosaki, T. Kakehi, G. Inoue, S. Kono, and H. Imura. 1989. Postreceptor defect in insulin action in streptozotocin-induced diabetic rats. Am. J. Physiol. 256:E624-E630.

42. Koopmans, S. J., S. F. De Boer, H. C. M. Sips, J. K. Radder, M. Frolich, and H. M. J. Krans. 1991. Whole body and hepatic insulin action in normal, starved and diabetic rats. Am. J. Physiol. 260:E825-E832.

43. Wallberg-Henriksson, H., and J. O. Holloszy. 1985. Activation of glucose transport in diabetic muscle: responses to contraction and insulin. Am. J. Physiol. 249:C233-C237.

44. Goodyear, L. J., M. F. Hirshman, S. M. Knutson, E. D. Horton, and E. S. Horton. 1988. Effect of exercise training on glucose homeostasis in normal and insulin-deficient diabetic rats. J. Appl. Physiol. 65:844-851.

45. Charron, J. M., and B. B. Kahn. 1990. Divergent molecular mechanisms for insulin-resistant glucose transport in muscle and adipose cells in vivo. J. Biol. Chem. 265:7994-8000.

46. Amatruda, J. M., and M. Roncone. 1985. Normal hepatic insulin receptor autophosphorylation in nonketotic diabetes mellitus. Biochem. Biophys. Res. Commun. 129:163-170.

47. Okamoto, M., M. F. White, R. Maron, and C. R. Kahn. 1986. Autophosphorylation and kinase activity of insulin receptor in diabetic rats. Am. J. Physiol. 251:E542-550.

48. Truglia, J. A., G. R. Hayes, and D. H. Lockwood. 1988. Intact adipocytes insulin-receptor phosphorylation and in vitro tyrosine kinase activity in animal models of insulin resistance. Diabetes. 37:147-153.

49. Block, N. E., K. Komori, K. A. Robinson, S. A. Dutton, C. F. Lam, and M. G. Buse. 1991. Diabetes-associated impairment of hepatic insulin receptor tyrosine kinase activity: a study of mechanisms. Endocrinology. 128:312-322.

50. Giorgino, F., J. H. Chen, and R. J. Smith. 1992. Changes in tyrosine phosphorylation of insulin receptors and a 170,000 molecular weight nonreceptor protein in vivo in skeletal muscle of streptozotocin-induced diabetic rats: effect of insulin and glucose. Endocrinology. 130:1433-1444. 